\title{
LA TECNOLOGÍA GEOESPACIAL COMO HERRAMIENTA DE PLANIFICACIÓN URBANA UTÓPICA DE LA CIUDAD DE TLAXCO, TLAXCALA, MÉXICO
}

\author{
GEOSPATIAL TECHNOLOGY AS A TOOL \\ FOR UTOPIC URBAN PLANNING IN THE CITY \\ OF TLAXCO, TLAXCALA, MEXICO
}

\section{RAMOS MONTALVO VARGAS \\ Universidad Autónoma de Tlaxcala (UAT),}

México

El objetivo del presente trabajo es analizar las condiciones de planificación urbana en el municipio de Tlaxco, Tlaxcala. La metodología empleada se basó en técnicas de análisis espacial y los resultados muestran que el espacio urbano proyectado para el crecimiento de la ciudad era de 622,6 hectáreas y 1384 adicionales como zona de conservación y parque urbano; sin embargo, actualmente el amanzanamiento oficial cubre 1786,6 hectáreas; es decir, 1164 sin una regulación planificada. La ausencia de capacidades técnicas y conocimiento al interior de los gobiernos municipales, provoca que planificar sea una ilusión; y, hacerlo con tecnología geoespacial, una utopía.

tecnología, espacio, planificación, ciudad, Tlaxco

\author{
MAYELA MONTSERRAT \\ GUTIÉRREZ CARREÓN \\ Investigadora independiente \\ Recibido: 3 de junio del 2019 \\ Aprobado: 6 de agosto del 2019
}

doi: 10.26439/limaq2020.n006.4817

This work aims to analyze the urban planning conditions in the municipality of Tlaxco, Tlaxcala. The methodology used in this research was based on spatial analysis techniques. The results showed that the urban space planned for city growth was 622.6 hectares, and an additional 1,384 hectares were planned for conservation area and urban park. However, the official squaring currently covers $1,786.6$ hectares; in other words, 1,164 are being invaded without a proper planning regulation. The absence of technical capabilities and knowledge within municipal governments causes planning to be an illusion; and, doing it with geospatial technology, a utopia.

technology, space, planning, city, Tlaxco 


\section{INTRODUCCIÓN}

En el presente documento se analizan aquellos elementos críticos que permiten afirmar la obsolescencia de la Carta Síntesis de Usos de Suelo Urbano ${ }^{1}$, instrumento fundamental en las decisiones de planificación en Tlaxco ante las discontinuidades urbanas, pues como bien señala Fariña (2015), la verdadera revolución en la organización espacial de la ciudad ha venido de la mano con la sustitución del concepto de distancia por el de tiempo; es decir, la ciudad crece a un ritmo tan acelerado que los instrumentos de planificación deben estar actualizados, porque de no hacerlo se corre el riesgo de pensar una ciudad con destino caótico en usos y destino del suelo periférico; y cuando se trata de recursos naturales adquiere dimensiones alarmantes para la población asentada en el entorno. Y Tlaxco, tiene una de las tres reservas naturales del estado de Tlaxcala, la cual ya se encuentra en los límites de la ciudad y cuyos efectos trastocan directamente el ecosistema.

En Tlaxco sucede lo que ya desde hace casi tres décadas ocurría en Europa y que en México ni siquiera era objeto de una discusión científica ante la carencia de recursos geoespaciales (técnicos y humanos): la localización espacial depende de una nueva serie de intereses que los tradicionales métodos de análisis en planificación no son capaces de instrumentar con la suficiente rapidez como lo están demandando los poderes públicos (Pueyo, 1991, p.177). La necesaria elaboración de instrumentos que ayuden a la actualización de la información, comprensión y nuevos métodos para la planificación y gestión urbana son impostergables.

Para lograr lo anterior, el uso de la tecnología geoespacial (que desde 1968 se considera el inicio de la era espacial moderna) se ha convertido en una herramienta fundamental para realizar labores de planificación, ordenación, gestión y administración del suelo urbano y rural. En México, desde 1988, la extinta Secretaría de Programación y Presupuesto (SPP), empezó trabajos en materia geotecnológica que se cristalizaron en la creación del actual Instituto Nacional de Estadística y Geografía (INEGI). Actualmente, la carrera espacial no ha tenido despunte en México porque hay una alta dependencia de conocimientos, desarrollos, datos y software especializado en la materia, principalmente de Estados Unidos. Lo anterior ha sido, entre otros aspectos, un obstáculo para que los gobiernos locales realicen labores de planificación urbana basada en el uso y manejo de datos geoespaciales.

En diversos gobiernos municipales de México hay un severo desconocimiento del alcance de la geomática, lo que ha impedido iniciar procesos de planificación urbana que parecen alcanzar una dimensión utópica, un sueño inalcanzable porque la capacidad de respuesta de los gobiernos locales es muy limitada respecto del dinamismo de las actividades en la vida urbana.

1 Conocida también como Programa Director Urbano. 
El estudio se realizó en la municipalidad de Tlaxco, que está ubicado en el estado de Tlaxcala y es la demarcación con mayor extensión territorial en la entidad federativa; pero a pesar de su amplitud en superficie y las 38 localidades que lo componen, no implica necesariamente que cuente con recursos suficientes tanto naturales como humanos para una eficiente administración del territorio. Muestra de ello es que las herramientas de gestión urbana son obsoletas, insuficientes y han sido rebasadas en sus procesos de actualización. Uno de los instrumentos fundamentales para tomar decisiones de uso, administración y gestión del suelo urbano es la Carta Síntesis de Usos de Suelo Urbano, que tiene 36 años de haber sido elaborada. Gobiernos salientes y entrantes no tienen los conocimientos en materia geoespacial para actualizar esta herramienta de decisión.

En la presente investigación se analiza la estructura espacial del mencionado instrumento en estado de obsolescencia y las ventajas de actualizarlo para sentar las bases en materia de georreferenciación y facilitar las labores de planificación, ordenación y gestión del suelo urbano central y periférico ante el crecimiento físico desordenado de una ciudad con casi veinte mil habitantes, pero que ha cobrado especial relevancia regional tras haber adquirido la denominación nacional de "Pueblo Mágico". Tlaxco y Huamantla son las dos únicas urbes con esta categoría en el estado de Tlaxcala, México.

En definitiva, las limitadas condiciones de infraestructura geoespacial para llevar a cabo procesos de planificación urbana parecen más que un sueño, una utopía donde el mundo académico está desvinculado del sector gubernamental por la falta de aceptación del conocimiento, apertura y ayuda para acceder a los inevitables y bondadosos recursos tecnológicos.

\subsection{El panorama utópico de la planificación en los municipios de México}

Las transformaciones que la tecnología provoca en los territorios son aplastantes, es un revulsivo del espacio urbano y rural. Las ciudades no están exentas y son las que más asimilan este proceso por su dinamismo interno; así, tecnología y ciudad parecen competir por su modernización; no obstante ser de naturaleza disímbola, crecen, modifican el entorno y hacen sentir su presencia.

A pesar del crecimiento tecnológico en distintas ramas de la ciencia y particularmente en la geografía; en múltiples espacios urbanos de México, está ausente la aplicación del conocimiento geotecnológico. Los vehículos aéreos no tripulados (VANT), también llamados drones, son conocidos y utilizados tan solo para el ocio, pero no para labores de planificación urbana. El uso de GPS en celulares, de herramientas como Google Earth, Map Server, entre otros, son de uso recreativo, pero no para tomar decisiones por parte de los gobiernos locales. Por lo tanto, ¿hasta cuándo las autoridades municipales en México harán uso de la tecnología geoespacial en tareas de planificación urbana? La respuesta está envuelta en una connotación utópica. 
Para contextualizar lo anterior, nos remitimos a 1988, cuando se crea la Secretaría de Programación y Presupuesto (SPP), encargada de realizar labores de planificación. Allí un grupo de expertos se formó en manejo de geotecnología y particularmente en materia de teledetección. Si bien el desarrollo computacional no iba a la par con las épocas y acontecimientos que se vivían (por ejemplo, la era espacial moderna que se inició en 1968 con la puesta en órbita del satélite Sputnik), en las oficinas del aparato gubernamental en México los conocimientos sobre tecnología geoespacial tardaron en llegar y eran escasos.

En el país se habla fuertemente de planeación ${ }^{2}$ en la esfera gubernamental hacia 1970. Las ideas de planificar eran fragmentos para lograr el desarrollo urbanístico asumido con un enfoque normativo y con el principio jerárquico de top-down, lo que se convirtió en un reto para los diseñadores urbanos; y no es sino 30 años después que la vigencia del término "ciudad fragmentada" empieza a recobrar sentido y reconocimiento ante el desproporcionado crecimiento, anárquico, expansivo e irregular de las ciudades. La reacción en ese momento fue pensar en soportes explícitos con instrumentos como planes de ordenamiento y programas de desarrollo urbano con el propósito de controlar el crecimiento de las ciudades; sin embargo, no se calcularon las implicaciones de la fuerza, el impacto y las inercias de una ciudad en franca y rápida expansión física.

En Tlaxco las fechas coinciden de manera fehaciente, la Carta Síntesis de Usos de Suelo Urbano data de hace 36 años y los demás programas vinculados a las actividades de intervención urbana en esa demarcación son algunos instrumentos inexistentes, otros imprecisos y otros desvinculados de la realidad y, por lo tanto, inoperantes.

A lo anterior se suman los cambios de personal cada tres años en las áreas potenciales de aprovechamiento geotecnológico en ese nivel de gobierno; el problema alcanza dimensiones tan alarmantes como soluciones impertinentes e imaginarias si lo que se busca es el diseño, elaboración y actualización de instrumentos de planificación urbana. En este panorama utópico está presente una discusión dicotómica de la tecnología: su presencia y ausencia. Presencia en el entorno, conocida y aceptada, pero también ausente en los espacios de trabajo, en las oficinas del gobierno municipal.

\section{2 ¿Por qué planificar el espacio urbano?}

Parece que la pregunta suena a una obviedad, pero no es así. Se ha olvidado esta labor fundamental en los últimos años; y no son tres décadas de crisis de la planificación urbana (Portas, 1996), sino que comienza con la falta de

2 En esta investigación los términos "planeación", "planificación" y "planeamiento", se emplearán para referirnos a la misma cosa; sin embargo, cabe aclarar que su diferencia conceptual radica en el diseño, instrumentación, aplicación e institucionalización, elementos que aquí no se discutirán. 
instrumentos para inducir el crecimiento de los centros de población en un imaginario ideal del que carecen no solo quienes diseñan la construcción, distribución, organización y funcionamiento del espacio urbano, sino, además de quienes se disponen a vivir en él.

En México no se busca un modelo universal como el de Haussmann para París; la intención de normar con planes generales o especiales en las últimas décadas derivó en la posibilidad de crear programas más bien parciales, algunos de los cuales eran para el desarrollo urbano. Sin embargo, la sensibilización técnica de los ejecutores y planificadores empezó a perder sentido porque las capacidades para su aplicación radicaban en unos cuantos. A lo anterior se suma la reciente incorporación al mundo geotecnológico de los gobiernos en México en sus esferas federal, estatal y municipal, pero la tortura y génesis utópica de la imposibilidad por aplicar esas herramientas a la par de las exigencias de la realidad empezó a tener su primer gran efecto: la desactualización de los primeros instrumentos de planificación urbana.

\section{METODOLOGÍA}

La metodología empleada en esta investigación tiene dos momentos, uno documental exploratorio de las condiciones de planificación urbana referidas a la carencia y obsolescencia de instrumentos jurídicos de planificación; y el segundo un análisis espacial con recursos geotecnológicos de la Carta Síntesis de Uso de Suelo Urbano, como ejercicio de reflexión.

El primer momento consiste en una revisión de la legislación en materia de planificación urbana, particularmente la que tiene incidencia en el espacio municipal; se revisó la legislación en materia urbana y se sondearon algunas áreas del gobierno municipal de Tlaxco con la finalidad de conocer la existencia de aquellos instrumentos de aplicación vigentes. Se encontró que la Carta Síntesis de Usos de Suelo Urbano, también llamada Programa Director Urbano, tiene una obsolescencia de casi cuatro décadas; y fue este instrumento la base del análisis porque a partir de él se deberían decisiones hoy en día. Asimismo, existe una desactualización de los planes de desarrollo urbano y de los planes parciales y especiales; sin embargo, a pesar de la inexistencia de programas de ordenamiento territorial y ecológico, así como del Atlas de Riesgos, estos en caso de elaborarse o actualizarse, son susceptibles de utilizar la tecnología geoespacial para su elaboración, o actualización.

En el segundo momento se emplearon algunos recursos básicos de teledetección y sistemas de información geográfica (SIG) para analizar el espacio urbano de la ciudad de Tlaxco y concluir que es necesario que las áreas estratégicas del gobierno municipal como catastro, obras públicas y servicios públicos comiencen un proceso de apropiación del conocimiento basado en el uso de la tecnología geoespacial y a partir ella comenzar labores de planeamiento urbano; de lo contrario, el panorama utópico será una constante. 
Figura 1.

Localización de Tlaxco, Tlaxcala

Elaboración propia con datos vectoriales del

INEGI, 2015

y de Google

Earth, 2019

\section{RESULTADOS}

El presente estudio se realizó en el municipio de Tlaxco, galardonado el 25 de septiembre de 2015 como "Pueblo Mágico", categoría alcanzada por su atracción turística cuya distinción fue hecha por la Secretaría de Turismo del Gobierno Federal Mexicano ${ }^{3}$. El municipio está ubicado al norte del Estado de Tlaxcala que es una de las 32 entidades federativas del país. Su cabecera municipal es el lugar con mayor cantidad de población (14 805) y una superficie urbana de 591,88 hectáreas.
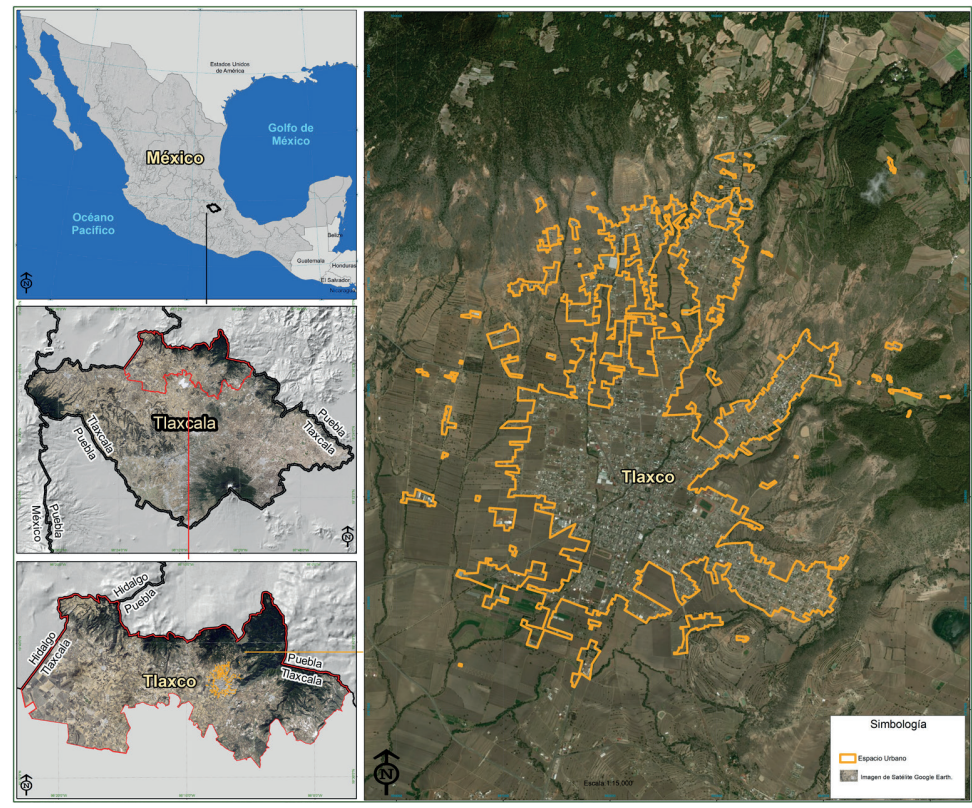

La búsqueda de evidencias que respaldan esta investigación se centró en la sede del poder público de esa demarcación, ubicado en la cabecera municipal, donde se recabaron evidencias documentales y se analizó la información recibida. En el siguiente apartado se discuten los principales resultados.

\subsection{La planificación urbana en Tlaxco: utopía y realidad}

La planificación urbana, para responder de manera normativa, necesita instrumentos suficientes pues busca regular las imperfecciones del mercado del suelo a través de planes urbanos, donde el suelo debe ser concebido a partir de la ciudad y no solo entendido como un espacio de uso y ocupación, sino como "un espacio de creación humana, un lugar de intercambio de bienes y

3 En México hay 121 pueblos mágicos. Tlaxco tiene una extensión territorial de 537,39 km² y es una de las tres reservas naturales con que cuenta el estado de Tlaxcala. 
cultura, un hervidero de ideas y conceptos, una amalgama de sus integrantes y un crisol de conocimientos" (Mendoza, 2017, pp. 12-16).

Después de revisar la normatividad aplicable en materia de planificación urbana, se pudo confirmar la desactualización e inexistencia de algunos instrumentos vinculantes aplicables y asociados al desarrollo urbano, así como el desconocimiento de otros documentos con contenido geotecnológico; en consecuencia, el camino por recorrer para solucionar esta problemática parece una condición de inminente carácter utópico.

Se encontró que la norma es muy diversa ${ }^{4}$, pero su escala de aplicación no permite a las áreas del gobierno municipal operar; de este modo, se dificulta su uso en la realidad. Asimismo, se reconoce que hacen falta instrumentos precisos, como los programas de ordenamiento territorial, de desarrollo urbano y el atlas de riesgos; pero deben tener protocolos para que el personal operativo haga un uso eficiente de ellos.

Sería ideal y utópico para Tlaxco, que la propuesta de un modelo de planeamiento se cultive y perfile desde un campo fértil de conocimientos, pero la planificación urbana ${ }^{5}$ en este lugar no se hace de esta manera (Boira, 2005), se atienden otras prioridades, porque la intervención administrativa en la materia crea un conflicto por la ausencia de reflexión sobre la expresión y representación de la ciudad. Un modelo busca desvanecer esa carencia vinculatoria entre realidad y labor del ente ejecutor; sin embargo, las áreas asociadas a esfuerzos de planificación en el municipio parecen dormidas, cuando menos impávidas.

Es necesario revalorar el enfoque geográfico como la disciplina fundamental que aporta a la planificación urbana (Baxendale, 2000); no obstante, con ejemplos como Tlaxco, esta actividad no se despolitizará, tampoco desaparecerá; la planificación tradicional está en su peor crisis en México desde su incipiente nacimiento, se ha convertido en una práctica artesanal y antiintelectual que solo actúa por reacción. Entretanto, el sector académico no puede solo quedarse como espectador encerrado en su torre de marfil, cada vez más alta (Hall, 1996, p. 371).

4 Se encontraron 19 documentos de base jurídica entre las leyes, reglamentos y programas que tienen injerencia en la planificación urbana de manera directa o indirecta; y entre los que tienen un aporte más directo se encontraron los siguientes: Ley General de Asentamientos Humanos, Ley de Planeación, Ley de Vivienda, Ley General de Turismo, Plan Nacional de Desarrollo 2019-2024, Programa Sectorial de Desarrollo Agrario, Territorial y Urbano, Ley de Asentamientos Humanos, Ordenamiento Territorial y Desarrollo Urbano del Estado de Tlaxcala, Ley de Ordenamiento Territorial y Asentamientos Urbanos para el Estado de Tlaxcala, Ley Municipal del Estado de Tlaxcala, Programa de Ordenamiento Territorial y Desarrollo Urbano para el Estado de Tlaxcala y el Programa Director Urbano de Tlaxco, también llamado Carta Síntesis de Usos de Suelo Urbano.

5 Los fundamentos de este trabajo están basados en el alcance de la geografía física y no de la geografía de la percepción. Más bien, aquí se fundamenta la realidad concreta de los usos de suelo en Tlaxco, Tlaxcala y no en la percepción de sus gobernantes u opinión de su población. 
Figura 2

Carta Síntesis de

Usos de Suelo

Urbano de

Tlaxco, Tlaxcala

Fuente: Dirección

de Obras Públi-

cas y Catastro de

Tlaxco, Tlaxcala

Como bien señala De Terán (1996), no solo es importante ver los aspectos teóricos, sino también los instrumentos de actuación. En la zona estudiada no se aprecia un sendero claro de planificación urbana, pero no es culpable el personal que labora en el gobierno municipal, es la inercia burocrática y el nulo reconocimiento de su institucionalización. Es normal, mantener vigente el uso de los instrumentos obsoletos por áreas del gobierno local; sin embargo, no se visualizan estrategias alternas en el corto plazo.

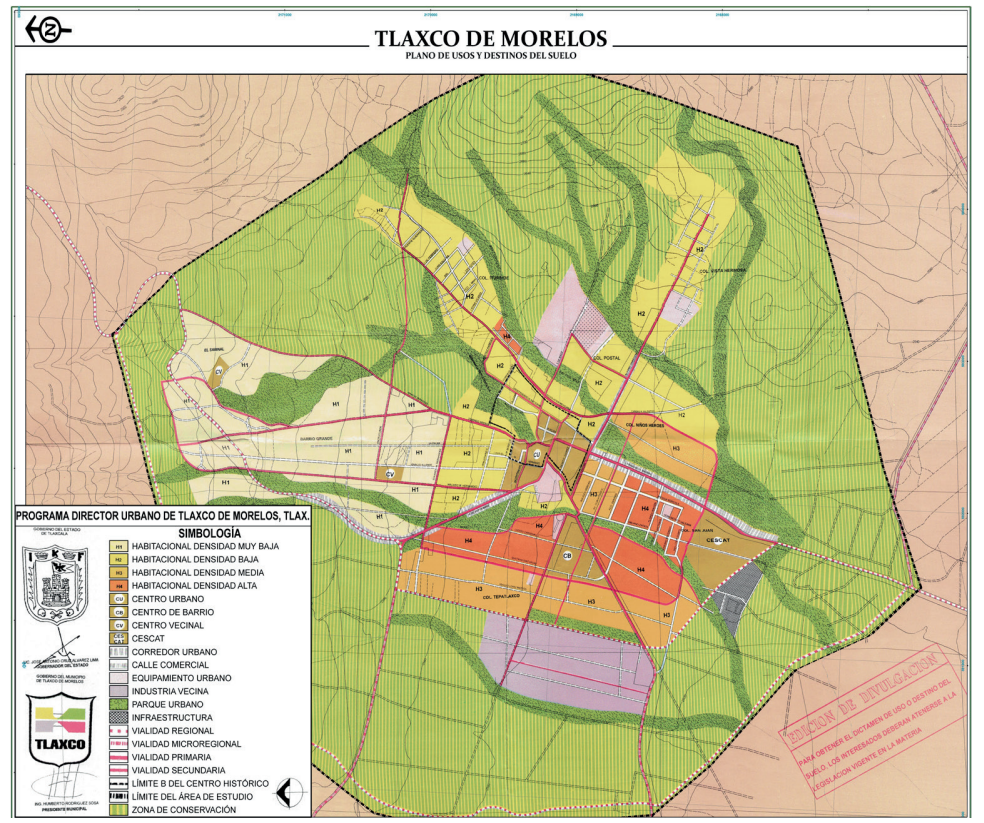

El instrumento evoca una amplia discusión operativa del concepto que acompaña la idea de planificación, además de la fragmentación, que es la condición de espacio urbano difuso a partir del cual se busca un control de ocupación basado en la estructuración, funcionalidad y gestión del territorio (Font, 2002, p. 7); y no se trata de reconocer o adoptar necesariamente un nuevo enfoque de planificación, sino de complementar ideas para abatir la complejidad de la ciudad. En Tlaxco, ciudad con 39939 habitantes y una concentración de 14806 (INEGI, 2010) en la cabecera donde hace referencia la Carta Síntesis Urbana, no parece todavía que las dimensiones del espacio urbano sean caóticas; pero llama la atención una dispersión elevada en su periferia, lo que provocará una fuerte presión del suelo por falta de infraestructura, equipamiento y servicios públicos, una carga del presupuesto público muy cuantiosa para el gobierno municipal. 


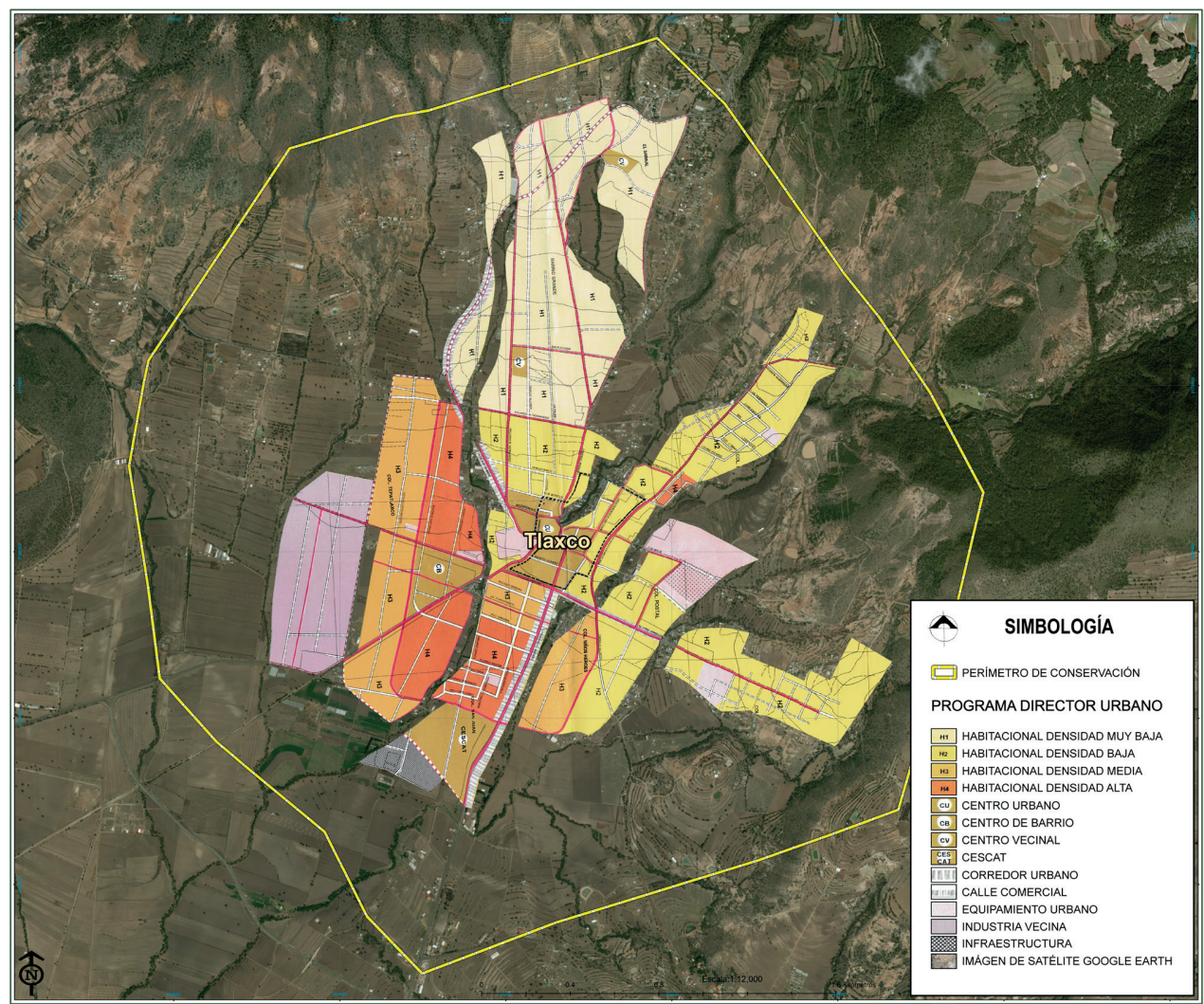

Los usos de suelo contemplados en el instrumento tienen un área de 622,6 hectáreas. Por otro lado, dadas las condiciones regionales y del entorno natural en que se localiza la ciudad, era prioritario dar una importante zona de amortiguamiento al espacio urbano en dirección al norte, respecto de su cercanía y contacto con la masa forestal densa y bosque mesófilo de montaña. Para ello, se consideró un polígono de conservación y parques urbanos con un total de 1384 hectáreas.

Asimismo, predomina la zona de conservación y parque urbano que es el área que envuelve la ciudad y que es representada por la poligonal semicircular; le sigue el espacio habitacional, con baja densidad en el norte y oriente donde se aprecia el crecimiento de las colonias Vista Hermosa e Iturbide. También se tenía la proyección de una densidad muy baja hacia la colonia El Sabinal

Figura 3.

Distribución

de los usos de suelo, polígono de conservación y zonas de crecimiento

\section{Elaboración}

propia con base en el Programa Director Urbano de Tlaxco (s / f) 
Tabla 1

Superficie por

usos de suelo de

la Carta Síntesis

Urbana

Elaboración

propia con

geoprocesos en

SIG

\begin{tabular}{lc}
\hline Categoría de uso de suelo & Superficie en hectáreas \\
\hline Calle comercial & 2,67 \\
\hline Centro de barrio & 11,52 \\
\hline Centro urbano & 18,41 \\
\hline Centro vecinal & 3,62 \\
\hline CESCAT & 16,81 \\
\hline Corredor urbano & 19,60 \\
\hline Equipamiento urbano & 27,30 \\
\hline Habitacional densidad alta & 59,15 \\
\hline Habitacional densidad baja & 173,97 \\
\hline Habitacional densidad media & 85,55 \\
\hline Habitacional densidad muy baja & 141,31 \\
\hline Industria vecina & 54,78 \\
Infraestructura & 7,91 \\
Zona de conservación y parque urbano & 1384,21 \\
\hline Suma & 2006,81
\end{tabular}

El instrumento de planificación, como se aprecia en el cuadro anterior, sí contempló zonas para el crecimiento, equipamiento y servicios complementarios $^{6}$; sin embargo, el crecimiento de la ciudad fue exponencial; y aunque los procesos urbanos no son espontáneos, hay una intervención voluntaria y la realidad urbana reclama nuevos modelos de organización urbana (De Terán, 1982). No obstante, algunos esfuerzos urbanísticos terminan siendo representaciones ilusorias y se convierten en sueños de planificación si no hay una sólida base de criterios científicos; con todo, no dejan de estar en el umbral de la utopía del pensamiento urbano.

La mutación de la estructura urbana en los municipios presenta especial atención en lo espacial-territorial, dimensión de análisis que prioriza medidas estratégicas para "la realización de obras públicas y a la gestión asociada entre actores públicos / privados para la implementación y la producción de infraestructuras y servicios" (Falú y Marengo, 2004, p. 216). Esa debería ser la preocupación central para el gobierno municipal de Tlaxco, pues la ciudad se ha desbordado en cinco ramales de su periferia, se ha vuelto dispersa, desordenada, irregular y descontrolada, lo que dificultará la cobertura de servicios necesarios para la población (Gutiérrez, 2019).

6 Se contemplaban 622,6 hectáreas y para el 2019 se tienen 591,88; sin embargo, el crecimiento no obedeció la disposición jurídica en usos y direcciones. 
A Tlaxco, al igual que a la gran mayoría de las ciudades en expansión en América Latina, le ocurre un fenómeno predecible que se repite incluso en algunas ciudades europeas, como el caso de Valencia (España) donde hubo un "enorme impacto ambiental y altísimo consumo de recursos escasos, como suelo, agua y energía; fortísimo impacto sobre el paisaje; imposibilidad de aportar las infraestructuras y los servicios públicos necesarios para atender tal volumen residencial" (Burriel de Orueta, 2009, p. 51). Lo anterior se puede apreciar en la siguiente figura, en que el crecimiento de la ciudad se orienta hacia el norte, donde se ubica la montaña y su zona forestal.

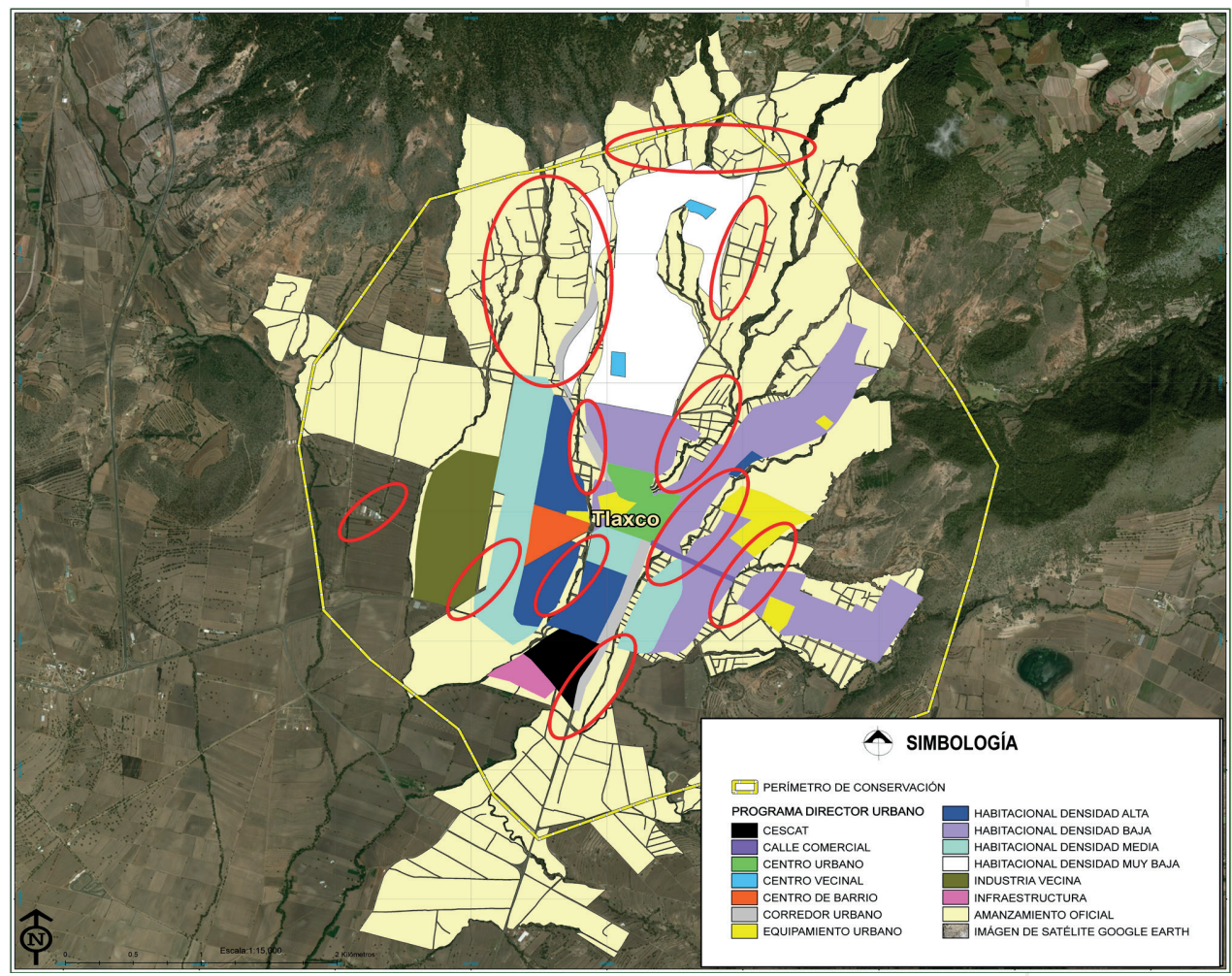

Con el amanzanamiento oficial de la ciudad se cubren 1786,6 hectáreas; y si se considera que el espacio urbano, para el año 2019, es de 591,88 hectáreas, hay 1194 hectáreas con potencial de uso urbano. Adicionalmente, si se toma en cuenta la estructura de la Carta Síntesis Urbana en condición de obsolescencia, serán 1164 hectáreas que se ven invadidas sin una regulación planificada. Lo anterior, permite concluir que, sin un rumbo claro de planificación urbana, la ciudad está condenada a triplicarse y crear un desorden físico en su estructura y ocupación futura. Con marcas ovales se señalan las zonas de crecimiento acelerado.

Figura 4.

Amanzanamiento de la ciudad de Tlaxco

\section{Elaboración}

propia con datos de INEGI, 2017 y Google Earth, 2019 
Dada la estructura de la Carta Síntesis de Usos de Suelo Urbano y la actual configuración urbana de la ciudad altamente dispersa, desordenada y expandida, la base del modelo que puede ayudar a Tlaxco parte de la idea de poner límites al crecimiento y racionalizar de manera óptima la estructura espacial de la ciudad, de lo contrario, la realidad y no una utopía, será el caos urbano acompañado de altos costos sociales, económicos y ambientales por la deficiencia no solo en la planificación, sino en los procesos de gestión, promoción de la ordenación y mala administración de su territorio.

Asimismo, hay que decir que la planificación urbana tampoco se da por decreto, involucra la intervención pública directa; pero también, las condiciones de un entorno positivo para regular y orientar la actividad y práctica urbanística a determinadas acciones de planificación, donde métodos basados en la voluntariedad y participación social es decisiva (Sánchez, 2000). Por tanto, el desarrollo participativo en un proceso de planificación urbana debe recuperar la importancia del usuario en el diseño (Olivares, 2017, p. 73); de no hacerlo, más allá de los discursos y las legislaciones, la utilización en la realidad de las herramientas del planeamiento público, se convertirán en instrumentos de exclusión y de conservación de la segregación (De Assis, 2018, p. 253).

Con lo anterior tampoco se afirma que la geotecnología es la única solución o una panacea, la ciudad contemporánea atiende nuevas formas de comunicación, simbolismo e identidades, elementos esenciales para diseñar un modelo de planificación. Asimismo, una cobertura eficiente de servicios es clave en los sistemas internos y periféricos, que tiene efectos positivos sobre la potencialidad del espacio urbano (Gutiérrez, 2019 y García, 2010); esa debe ser la finalidad última de la Carta Síntesis de Uso de Suelo de Tlaxco, servir de referente para estimular el potencial de uso del espacio con criterios que anticipen el caos urbano y rural.

\section{CONCLUSIONES}

Con el análisis espacial que se hizo de la Carta Síntesis de Uso de Suelo Urbano de la cabecera municipal de Tlaxco y su composición de usos del suelo, se percibe un problema complejo donde el desbordamiento multidireccional y crecimiento exponencial de ciudad se aleja de la configuración de un modelo ideal. Con 591,88 hectáreas efectivas de espacio urbano y 1786,6 hectáreas de área con potencial de uso, resultado de la dispersión, anarquía, desorden y crecimiento caótico, la estructura y ocupación futura de la ciudad de Tlaxco reclama con urgencia estrategias de solución inteligentes e inmediatas. Esa es la realidad y su planificación a partir del uso de la geotecnología, una mera utopía.

Para que la planificación tenga frutos, es necesario un plan estratégico e instrumentos específicos; en Tlaxco solo se tiene una Carta Síntesis de Usos de Suelo Urbano con casi cuatro décadas de haberse creado y documentos normativos desvinculados de la realidad social, difíciles de entender y ajustar por parte de las autoridades, con poco tiempo para aprender, aplicar y desarrollar 
su entorno. Asimismo, las leyes en la materia en Tlaxcala señalan que estos instrumentos deben actualizarse cada seis años. Visto así, esto aleja la esperanza, adormece los anhelos e invoca a la utopía.

Es necesario y urgente actualizar la Carta Síntesis de Usos de Suelo Urbano de Tlaxco y sensibilizar, a la vez, el aparato burocrático para romper esas falencias de administrar el territorio sin un alto nivel de conciencia sobre las implicaciones que tiene realizar este trabajo sin un marco normativo que concuerde con la realidad y con un personal carente de conocimientos para emprender iniciativas de planificación a través de la tecnología geoespacial que un aspecto básico en la mayoría de los instrumentos de intervención moderna.

Es fundamental formar un capital humano especializado e institucionalizar la planificación no solo urbana, sino territorial en las administraciones municipales para evitar que los cambios de gobierno afecten la continuidad y diferenciación en el diseño, elaboración e implementación de los instrumentos operativos.

En definitiva, las carencias, omisiones y el desgaste institucional por atender problemas distintos a la falta de planificación, reconfiguran un panorama utópico, un imaginario cada vez más obscuro, donde las bondades que ofrece la tecnología geoespacial son una posibilidad, una alternativa, una esperanza; el resto lo dará el conocimiento, disciplina y esfuerzo constante.

Para superar los obstáculos que colocan a la planificación urbana en Tlaxco en un estado utópico, se deben adoptar métodos avanzados y apropiados para lograr cambios estructurales que tengan una base geotecnológica; no es suficiente razonar y comprender el problema, es necesario superar las limitaciones culturales, temporales y de costos sociales, políticos y económicos por no iniciar el proceso de planificación. Lograr la concreción del alcance estructural de esta recomendación supone más un imaginario utópico que una aproximación a la realidad.

\section{REFERENCIAS}

Baxendale, C. A. (2000). Geografía y Planificación urbana y regional: una reflexión sobre sus enfoques e interrelaciones en las últimas décadas del siglo XXI. Reflexiones Geográficas, (9), pp. 58-70.

Boira I. M. y Josep V. (2005). Planeamiento sin percepción, educación sin participación. Recuperado de http://www.cervantesvirtual.com/nd/ark:/59851/bmcx3564

Burriel de Orueta, E. L. (2009). Los límites del planeamiento urbanístico municipal. El ejemplo valenciano. Anales Geográficos, (53), pp. 33-54.

De Assis Libânio, C. (2018). Lugares de urbanidad metropolitana (Lumes). Planeamiento compartido y enfrentamiento de la pseudoparticipación en la región metropolitana de Belo Horizonte. Limaq, (4) pp. 247-268. 
Falú, A. y Marengo, C. (2004). Las políticas urbanas: desafíos y contradicciones. El rostro urbano de América Latina, Buenos Aires: Consejo Latinoamericano de Ciencias Sociales (Clacso).

Fariña, J. (2015). Cambiar el modelo urbano. Ciudades, 1(18), pp. 69-79.

Font, A. (2002). La renovación del planeamiento urbanístico. Ciudades, pp. 77-81.

García, R. (2010). Crecimiento urbano y modelo de ciudad. ACE: Architecture, city and environmental, 12, A, pp. 51-58.

Gutiérrez, M. (2019). Modelo de planeamiento urbano de la ciudad de Tlaxco a partir de servicios públicos municipales (tesis de maestría). El Colegio de Tlaxcala, Tlaxcala, México.

Hall, P. (1996). Ciudades del mañana. Historia del urbanismo en el siglo xx. Barcelona: Del Serbal.

Instituto Nacional de Estadística y Geografía (INEGI). (2017). Datos vectoriales del marco geoestadístico nacional. México. Recuperado de: https://www.inegi. org.mx/temas/mg/

Mendoza, A. (2017). La planificación urbana como proceso regulador del mercado del suelo urbano y generador de vivienda social. Limaq, (3), pp. 11-20.

Olivares, E. (2017). De la vivienda a la ciudad: Arquitectos de Cabecera, una propuesta alternativa de planificación bottom-up. Limaq, (3), pp. 61-74.

Portas, N. (1996). El planeamiento urbano como proceso de regulación variable. Ciudades, (3), pp. 97-109.

Pueyo, A. (1991). El sistema de información geográfica un instrumento para la planificación y gestión urbana. Geographicalia, (28), pp. 175-192.

Sánchez de Madariaga, I. (2000). Nuevos enfoques del planeamiento. Urban, (4), pp. 31-37.

Terán, F. de. (1996). Evolución del pensamiento urbanístico (1846-1998). Ciudad y Territorio, Estudios Territoriales, 28, pp. 167-184.

Terán, F. de. (1982). El problema urbano. Temas Clave (82). Barcelona: Salvat Editores. 